\title{
A new conceptual model for quantifying transboundary contribution of atmospheric pollutants in the East Asian Pacific rim region
}

I-Chien Lai ${ }^{1}$, Chon-Lin Lee ${ }^{1,2,3,4^{*}}$, Hu-Ching Huang ${ }^{1}$

1 Department of Marine Environment and Engineering, National Sun Yat-sen University, Taiwan

2 Kuroshio Research Group, Asia-pacific Ocean Research Center, National Sun Yat-sen University, Taiwan

3. Department of Public Health, College of Health Sciences, Kaohsiung Medical University, Kaohsiung, Taiwan

4. Research Center of Environmental Medicine, College of Health Sciences, Kaohsiung Medical University, Kaohsiung, Taiwan

* Corresponding author at:

Department of Marine Environment and Engineering,

National Sun Yat-sen University, 70 Lienhai Rd., Kaohsiung 80424, Taiwan

Tel.: +886 75252000 ext. 5066; Fax: +886 75255066 .

E-mail address: linnohc@mail.nsysu.edu.tw (C-L Lee). 


\begin{abstract}
Transboundary transport of air pollution is a serious environmental concern as pollutant affects both human health and the environment. Many numerical approaches have been utilized to quantify the amounts of pollutants transported to receptor regions, based on emission inventories from possible source regions. However, sparse temporal-spatial observational data and uncertainty in emission inventories might make the transboundary transport contribution difficult to estimate. This study presents a conceptual quantitative approach that uses transport pathway classification in combination with curve fitting models to simulate an air pollutant concentration baseline for pollution background concentrations. This approach is used to investigate the transboundary transport contribution of atmospheric pollutants to a metropolitan area in the East Asian Pacific rim region. Trajectory analysis categorized pollution sources for the study area into three regions: East Asia, Southeast Asia, and Taiwan cities. The occurrence frequency and transboundary contribution results suggest the predominant source region is the East Asian continent. This study also presents an application to evaluate heavy pollution cases for health concerns. This new baseline construction model provides a useful tool for the study of the contribution of transboundary pollution delivered to receptors, especially for areas deficient in emission inventories and regulatory monitoring data for harmful air pollutants.
\end{abstract}

Keywords: Back trajectory; East Asia; Particulate matter; Particulate polycyclic aromatic hydrocarbons; Pollutant source region 


\section{Introduction}

The adverse impacts of air pollutants (e.g., particulate matter (PM), ozone, and persistent organic pollutants) on human health and the environment are well recognized (Brunekreef and Holgate 2002; Krewski et al., 2009; WHO 2003, 2006). Their effects are not limited to emission sources in the nearby area only, as atmospheric pollutants can be transported from their source regions to different continents (receptor regions), even on a global scale (Akimoto 2003; Jaffe et al., 1999; Lelieveld et al., 2002;Wilkening et al., 2000; Zhang et al., 2008).

For PM pollution, the particle concentration, surface area, and composition (e.g., organic and inorganic compounds) are important factors that mediate the effects of PM on human health (Daigle et al., 2003; Lighty et al., 2000). Many studies indicate that PM pollution is associated with cardiovascular mortality and respiratory diseases (Kaiser 2005; Krewski et al., 2009; Laden et al., 2006; Pope III et al., 2002, 2004), and can even affect the central nervous system (Block and Calderón-Garcidueñas 2009; Calderón-Garcidueñas et al., 2008; Genc et al., 2012; Kim et al., 2010). Exposure to fine particles, defined by aerodynamic diameter $<2.5 \mu \mathrm{m}$ (PM2.5), has been demonstrated to have a particularly high risk of daily mortality and a long-term risk of death (Kaiser 2005; Krewski et al., 2009; Laden et al., 2000). These particles can also be transported over longer distances when compared with coarse particles (e.g., PM10) (Jeong et al., 2011; Lin et al., 2005; Nam et al., 2009). The toxicity of particulates also varies depending on their chemical composition. For instance, the adsorption of some carcinogenic polycyclic aromatic hydrocarbons (PAHs) by PM may increase the health risks of PM. Particle-bound PAHs may result in health effects with more severity than are observed with PM alone (Grimmer 1983; IARC 1984; WHO 2006).

Modeling approaches have been widely used for the study of air pollutant transboundary transport patterns (Chin et al., 2007; Mauzerall et al., 2000; Wagstrom 
and Pandis 2011; Wang et al., 2009; Zhang et al., 2008; Zhang et al., 2011) and for investigating the effects of transboundary transport on air quality in receptor regions (Huebert et al., 2003; Kajino et al., 2013; Lin et al., 2005; Lin et al., 2007; Naja and Akimoto 2004; Primbs et al., 2007; Yang et al., 2007), particularly the East Asian region. These studies have provided valuable knowledge for understanding transport patterns and the atmospheric pollutant impacts on potential receptors. However, the accuracy of input parameters, model selection, and the transboundary contribution algorithms might increase either the burden of simulation work or the uncertainty of the output.

Over the past few decades, the rapid economic growth and urbanization of East Asia has led to unprecedented atmospheric pollution. Some studies have indicated that emission inventory uncertainty and sparse observation data in the East Asian continent make the understanding of the relationship between the sources and the receptors - and therefore the quantification of the transboundary transport delivered to the receptors - a significant challenge (Chen et al., 2013; He et al., 2011; Wang et al., 2011; Zheng et al., 2009). An alternative method could be useful for quantifying atmospheric pollution imported from neighboring countries for those areas lacking emission inventories or regulatory monitoring of harmful pollutants.

Taiwan is the primary receptor located in the western Pacific region, which is a critical area for studying the impacts of air pollution exported from the East Asian continent. The objectives of this study are therefore to determine the seasonal variation of atmospheric pollutants for a metropolitan area in southwestern Taiwan and to construct an alternative method for quantifying the transboundary transport contribution of particulate pollutants in a metropolitan area by using back trajectory analysis to select baseline database from two-year monitoring data sets of particulate matter (PM10 and PM2.5) and PAH data. 


\section{Methodology}

\subsection{Particulate matter data}

The present study investigated the transboundary transport contribution of PM for the study area using hourly particulate matter (PM10 and PM2.5) concentration data from the Qianzhen station. This is the closest air quality monitoring station to the PAH sampling site (Figure 1) in the Taiwan Air Quality Monitoring Network (TAQMN). The PM data quality control is based on the Taiwan EPA Data Quality Assurance Procedures (DQAP), which follow those prescribed by the U.S. Environmental Protection Agency, established in 1991. The DQAP covers regular system maintenance (e.g., daily zero and span checks, biweekly precision checks, and monthly instrument function checks) and data performance auditing (TaiwanEPA 2014). In this study, a valid PM daily concentration was defined as the average of at least sixteen hours of effective data within a 24-hour collection to provide a better representative daily average. The data were collected for the study period of May 2007 to April 2009. Hourly meteorological data, including air temperature, rainfall, wind speed, and wind direction, were collected from the monitoring station of the Central Weather Bureau.

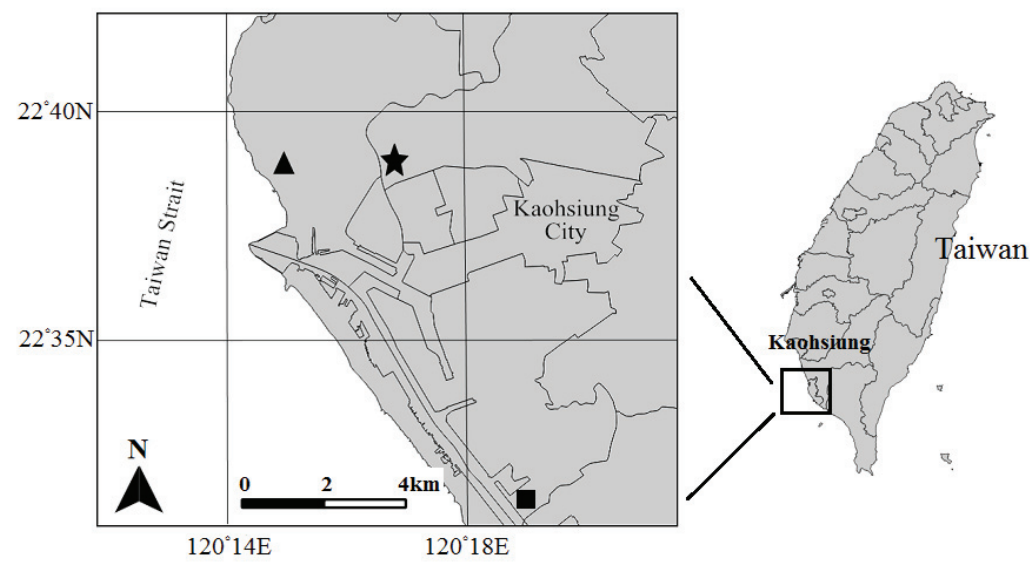

Figure 1. Map of the sampling sites. The star symbol indicates the location of the PM10 and PM2.5 monitoring site, the triangle symbol represents the location of the PAH sampling site, and the square symbol represents the location of the meteorological data monitoring site. 


\subsection{PAH data}

Particulate PAH data were collected at the university campus $\left(22^{\circ} 37^{\prime} \mathrm{N}, 120^{\circ} 15^{\prime} \mathrm{E}\right.$, Figure 1) between May 2007 and April 2009 [these data sets were also used in (Lai et al., 2011, 2013)]. The data of sixteen PAHs designated as priority pollutants by the US Environmental Protection Agency (U.S.EPA 1982), as well as BaP data, were selected for estimating the transboundary transport contribution. Detailed methods of sampling processes, equipment pre-treatment procedures, and sample extraction, preparation, and analysis procedures were published previously (Lai et al., 2011). The PAH data quality control was ensured by performing the measurements of field and laboratory blanks simultaneously. In addition, four perdeuterated PAHs (naphthalene- $\mathrm{d}_{8}$, fluorene- $d_{10}$, fluoranthene- $d_{10}$, and perylene- $d_{12}$ ) were utilized as surrogates for the determination of the efficiency of the sample extraction and analysis. Two-year observation samples were analyzed separately, with mean recoveries of $57.1 \pm 15.2 \%$ and $56.4 \pm 11.9 \%$ for naphthalene- $\mathrm{d}_{8}, 69.8 \pm 14.0 \%$ and $77.1 \pm 16.6 \%$ for fluorene- $\mathrm{d}_{10}$, $73.2 \pm 17.4 \%$ and $87.2 \pm 25.5 \%$ for fluoranthene- $\mathrm{d}_{10}$, and $78.3 \pm 10.5 \%$ and $92.0 \pm$ $19.3 \%$ for perylene- $\mathrm{d}_{12}$ for the period of May 2007-April 2008 and May 2008-April 2009, respectively.

Sampling limitations resulted in only 52 valid data measurements in the two-year collection. Given the evaluation of the transboundary PAH transport contribution, a multiple linear regression analysis (MLR) was utilized to simulate the concentrations of PAHs for the study period. Based on the results of the statistical significance (see Table S1) and the ability to predict concentrations, the parameters of PM10, temperature, and relative humidity were selected for multiple regression analyses of the 16 PAHs and $\mathrm{BaP}$. The equation of the multiple regression is:

$y=\alpha+\beta_{1} x_{1}+\beta_{2} x_{2}+\beta_{3} x_{3}$ 
where $\mathrm{x}$ is the independent variable (the values of three parameters: PM10, temperature, and relative humidity), $y$ is the value of the dependent variable for values $\mathrm{x}$ of the independent variables, and $\alpha, \beta_{1}, \beta_{2}$, and $\beta_{3}$ are regression coefficients. The comparison of the simulated and measured PAH concentrations (sixteen PAHs and $\mathrm{BaP}$ ) is shown in Figure $\mathrm{S} 1$. In general, the simulated PAH concentrations, for both the 16 PAHs and $\mathrm{BaP}$, showed a moderate correlation with the observations (the R-squared values are 0.576 and 0.559 for the sixteen PAHs and $\mathrm{BaP}$, respectively). The results from the year 2008-2009 performed better in the simulation than did the data for the year 2007-2008. In this study, the 52 PAH data measurements replaced the simulated data on the same days to investigate the transboundary pollutant transport with PM.

\subsection{Back trajectory analysis}

Air trajectory models have been used to study the dynamic processes of the atmosphere for several decades (Draxler and Rolph 2014; Rolph 2014). The present study used the Hybrid Single-Particle Lagrangian Integrated Trajectory (HYSPLIT) model (Draxler and Rolph 2014; Rolph 2014) to study the transboundary transport pathways of PM and PAHs from potential emission source regions to the study area. The back trajectories were estimated by getting the model to calculate the three-dimensional air mass trajectories (height, longitude, and latitude) in six-hour intervals over 72 hours. The time period for the back trajectory calculation was selected according to air mass traveling time and the distance between the study area and the potential source regions (Lang et al., 2007; Yang et al., 2007). The atmosphere was divided into three layers above the ground level: $100 \mathrm{~m}, 500 \mathrm{~m}$, and $1500 \mathrm{~m}$. The level selection was used to observe how the pollutant transport varies from the surface to the boundary layer. The meteorological data source for calculating back trajectory in 
this study was the GDAS (Global Data assimilation System). The data are available in $1 \times 1$ degree resolution, with 23 vertical levels (from $1000 \mathrm{hPa}$ to $20 \mathrm{hPa}$ ) and 35 parameters (e.g., pressure, relative humidity, temperature, and wind components, etc.). Cluster analysis was utilized to facilitate the trajectory classification. The predominant transport pathways categorized by cluster analysis for the study area are shown in Figure S2.

\subsection{Quantification of transboundary contribution}

The transboundary contribution to the study area was estimated by categorizing the transboundary transport days (TBDs) and non-transboundary transport days (NTBDs) based on the characteristics of the back trajectories. In this study, the day in which an air mass passed through any of the source regions in the territories out of the administrative boundary of Kaohsiung city in a 72-hour period was defined as a TBD. On the other hand, the day in which either a moving air mass did not travel across any source region in the territories or an air mass only travelled around the administrative boundary of Kaohsiung city in a 72-hour period was designated as an NTBD. Note that the definition of NTBDs (baseline days), in this study, is the days affected only by local pollution (from Kaohsiung city) and does not infer days without pollution. The concentrations of NTBDs were selected to establish the local pollutant concentration baseline in order to simulate the baseline concentration of TBDs.

Two curve fitting models - a third-order polynomial model and a Gaussian model - were used to simulate the daily baseline concentration for two years. The dataset selected for the simulation consisted of the daily average concentrations of PM10, PM2.5, and PAHs. Here, the date of the NTBDs was converted into the Julian Day Calendar (1-365 days for regular years, whereas 1-366 days for leap years) to acquire the relationship between the NTBD concentrations and the day number in the 
two-year study period. The equation of the third-order polynomial interpolation is:

$y=a+b x+c x^{2}+d x^{3}$

where $\mathrm{x}$ is the independent variable (the day number of year), $\mathrm{y}$ is the value of the dependent variable for a value of the independent variable $\mathrm{x}$, and $\mathrm{a}, \mathrm{b}, \mathrm{c}$, and $\mathrm{d}$ are the coefficients obtained from the relationship between the day number and the concentrations of NTBDs (Ayyub and McCuen 1996).

The Gaussian function is the exponential of a quadratic function and has the form:

$\mathrm{y}^{\prime}=\mathrm{a}^{\prime} * \exp \left(-0.5 *\left(\left(\mathrm{x}^{\prime}-\mathrm{b}^{\prime}\right) / \mathrm{c}^{\prime}\right)^{2}\right)$

where $x^{\prime}$ is the day number of year, and $y^{\prime}$ is the output value of the function corresponding to $\mathrm{x}^{\prime}$. The parameter $\mathrm{a}^{\prime}$ is the height of the curve's peak, $\mathrm{b}^{\prime}$ is the position of the peak center, and $\mathrm{c}^{\prime}$ is the standard deviation. The performance of the two models was calculated using the indicators of the coefficient of determination $\left(\mathrm{R}^{2}\right)$ and the root mean squared error (RMSE). Table S2 shows the values of the two indicators and suggests that the performance of the cubic polynomial model is slightly better than the Gaussian model. Therefore, we only present the baseline prediction results from the cubic polynomial model in this study. A baseline comparison between the observation and simulation values (from polynomial cubic function) is shown in Figure S3. The simulation baseline values exhibit the same seasonal trend as is seen with the measured values. The observed baselines of PM were the concentrations of NTBDs; on the other hand, the baseline values of PAH NTBDs were derived mostly from MLR simulated values, as there were only eight measurement data available.

Based on the results of the baseline prediction, the assessment of the transboundary transport contribution equation can be written as follows:

Transboundary Contribution $(\%)=\frac{\left.\sum_{i=1}^{N}\left[M_{i}-B P_{i}\right) M_{i}\right]}{N} \times 100 \%$

where $\mathrm{N}$ is the number of TBDs, $M_{i}$ is the measured concentration of TBDs, and 
$B P_{i}$ is the prediction value of the baseline.

\section{Results and discussion}

3.1 Atmospheric pollution scenarios

PM10 and PM2.5 have a nearly identical seasonal distribution, with their highest concentrations occurring during the winter (December, January, and February) and the lowest in the summer (June, July, and August) (Figure S4). The monthly concentrations of PM10 and PM2.5 ranged from 31.3 to $124.6 \mu \mathrm{g} \mathrm{m}^{-3}(73.0 \pm 28.9 \mu \mathrm{g}$ $\left.\mathrm{m}^{-3}\right)$ and 15.8 to $73.6 \mu \mathrm{g} \mathrm{m}^{-3}\left(47.1 \pm 19.1 \mu \mathrm{g} \mathrm{m} \mathrm{m}^{-3}\right)$, respectively. The annual average concentrations of both PM10 and PM2.5 in the study area were higher than those in Taipei $\left[44.0 \mu \mathrm{g} \mathrm{m}^{-3}\right.$ and $30.3 \mu \mathrm{g} \mathrm{m}^{-3}$, respectively; (Chang et al., 2010)] and exceeded the EPA annual standards of 65 and $15 \mu \mathrm{g} \mathrm{m}^{-3}$, respectively (TaiwanEPA 2014). A further investigation of the daily average data showed that 67 days of PM10 (9.3\% of total days, $\mathrm{N}=722)$ and 443 days of PM2.5 (60\% of total days, $\mathrm{N}=729)$ exceeded the current 24-hr standard during a two-year observation. The PM2.5 concentration was about three times the annual average $\left(15 \mu \mathrm{g} \mathrm{m}^{-3}\right)$ of the Taiwan EPA standard. These results suggest that the effects of PM2.5 on the study area are probably more evident than those of PM10, although the data quality of PM2.5 still needs to be carefully considered (TaiwanEPA 2014). Regarding PAHs, the measured daily and simulated monthly mean variations of a total of sixteen PAHs and BaP are shown in Figure S5. For the sixteen PAHs, the simulated total concentrations were between 0.041 and 8.65 $\mathrm{ng} \mathrm{\textrm {m } ^ { - 3 }}$, with an average of $1.55 \pm 1.22 \mathrm{ng} \mathrm{m}^{-3}(\mathrm{~N}=703)$. The BaP concentration varied from 0.0005 to $0.49 \mathrm{ng} \mathrm{m}^{-3}$ (average $0.10 \pm 0.07 \mathrm{ng} \mathrm{m}^{-3}, \mathrm{~N}=719$ ). Note that the variation in the PAH concentrations exhibited a similar seasonal pattern to that of the PM (Figures S4 and S5B). 


\subsection{Back trajectory analysis}

Five representative back trajectories as examples, illustrating different transport pathways and possible source regions for the study area, are shown in Figure 2. Figure 2A shows that the 72-hr back trajectories at three altitudes of $100 \mathrm{~m}, 500 \mathrm{~m}$, and 1500 m mainly originated from low-polluted maritime air masses that did not pass through any continental regions outside of the administrative boundary of Kaohsiung City. Atmospheric pollutant concentrations observed under these circumstances were classified as a background type and were used as a baseline simulation database, named Type B. The concentrations of the days defined as Type B were selected as the data for the baseline simulation of atmospheric pollutants. Figure $2 \mathrm{~B}$ shows air masses originating from the East Asian continent, named Type EC, which mainly passed through areas of intensive industrial activity on the east coast or northern China. Type EC, primarily observed during the spring and winter seasons, is related to the transboundary transport phenomenon and usually is accompanied by pollution from other cities in Taiwan. Type JK air masses from neighboring countries passed through Japan and Korea (Figure 2C). Type SA air masses from Southeast Asia (e.g., Vietnam, Liao, Thailand, Malaysia, and the Philippines) carried less pollution in comparison with those from the East Asian continent (Figure 2D). Type SA air masses usually occurred in the summer, accompanied by high humidity and strong convective activity (e.g., summer monsoon activity), which favor atmospheric pollutant dispersion. The back trajectories of Type TC were mainly related to the pathway transported through other cities in Taiwan (Figure 2E). The air mass characteristics of Type TC were associated with a weaker atmospheric circulation in comparison with the other 
transboundary transport types and were usually observed during the spring and autumn seasons. These transport patterns are similar to the air mass classification reported for Taiwan from 1993 to 2006 (Junker et al., 2009).
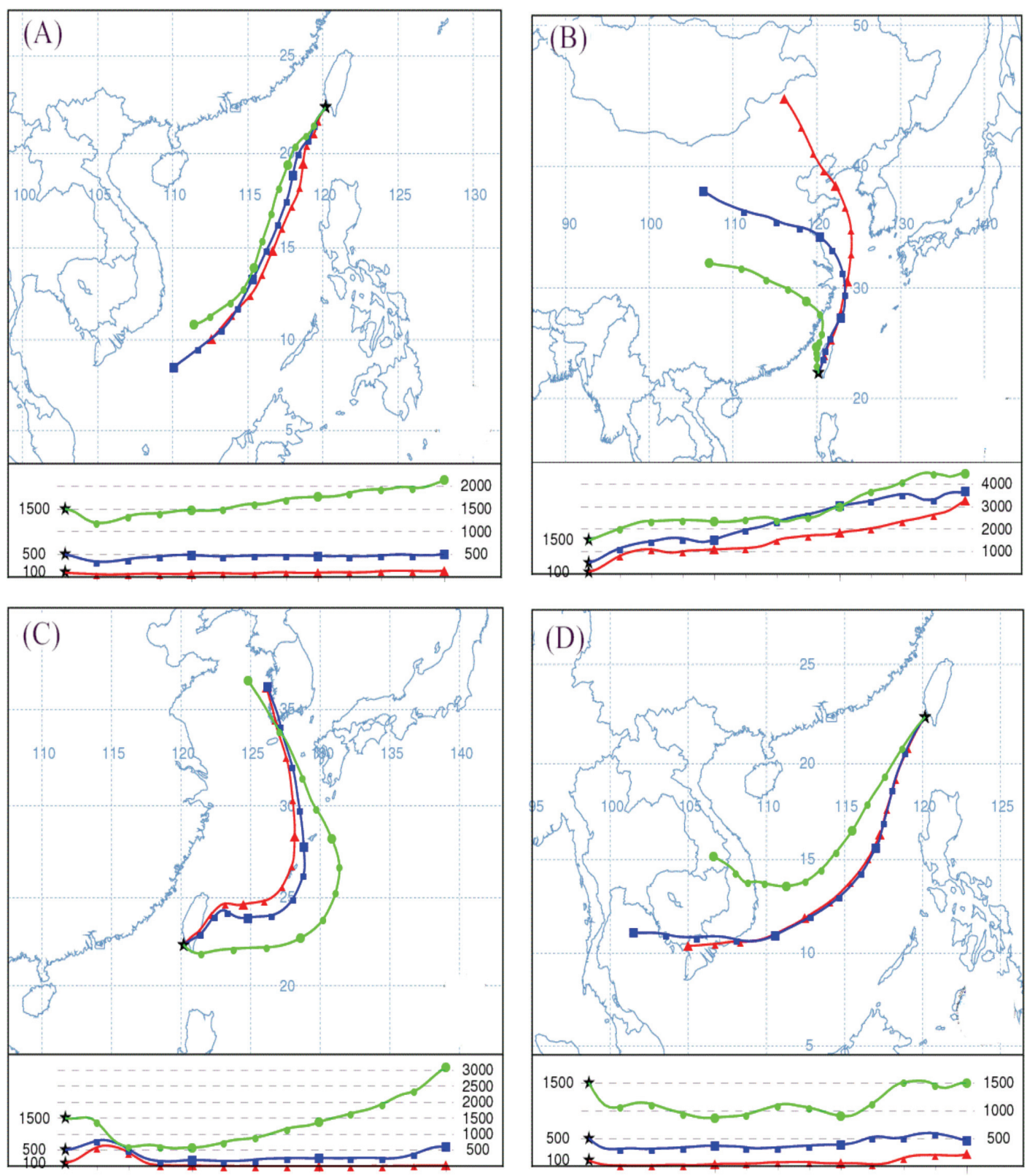


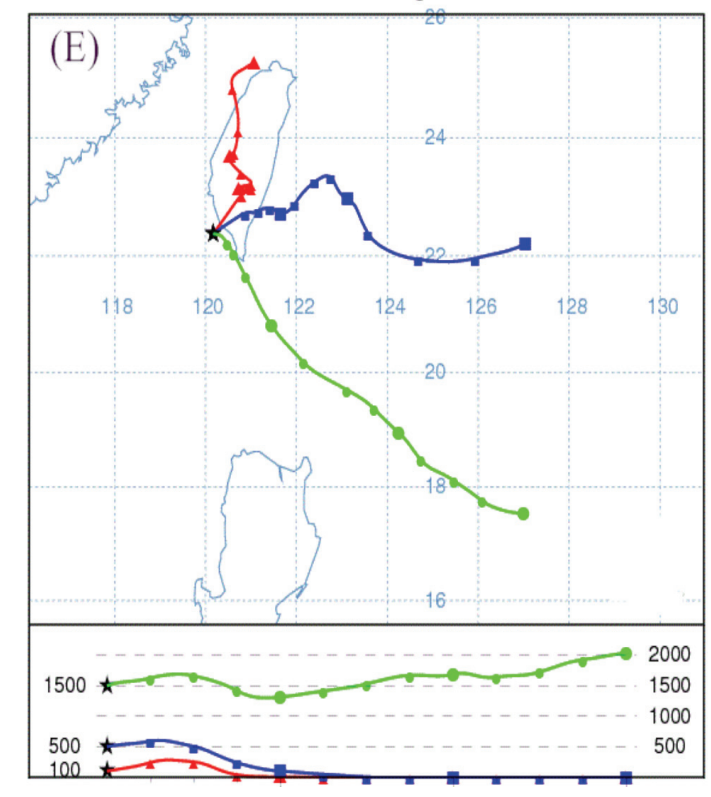

Figure 2. Back trajectory analysis of air samples. The 72-hr back trajectories for five representative transport pathways during a 2-year study period. (A) Type B, (B) Type EC, (C) Type JK, (D) Type SA, and (E) Type TC. The triangle symbol represents trajectory at the $100 \mathrm{~m}$ level, the square symbol represents trajectory at the $500 \mathrm{~m}$ level, and the circle symbol represents trajectory at the $1500 \mathrm{~m}$ level.

\subsection{Contributions from transboundary pollutant transport}

The results of the transport pathway distinction of the back trajectory analysis indicated that four transboundary transport types (Type EC, JK, SA, and TC) were usually accompanied by pollution from other cities in Taiwan and formed hybrid types of air masses. For instance, the air masses from the East Asian continent combined with the pollution from Type TC and were named Type ET. The other hybrid types included Types EJ, JT, EJT, and SAT. The Type JT and Type EJT both originate from the East Asian continent; however, the endpoints of the back trajectories for these two types are located in different territories. The transboundary transport contributions to the study area between these two types differ in degree; therefore, there is a need to distinguish these two types and also to retain type classification consistency.

The transport pathway characteristics showed that the source regions can be classified into three categories: (1) East Asia (Type EC, JK and their hybrid types), (2) Southeast Asia (Type SA and SAT), and (3) Taiwan cities (Type TC). Figure 3 
illustrates the average of the TBD contributions and the frequencies of TBD occurrences for these three source regions during the two-year observation. The dominant source region is the East Asian region, including China, Korea, and Japan. The estimated average PM (PM10 and PM2.5) contributions from the source regions ranged from 39.5-43.1\% (China), 35.6-35.9\% (Korea and Japan), 23.2-25.1\% (Southeast Asia), and 39.7\% (Taiwan cities) (Figure 3A and Table S3). The frequencies of the TBD occurrences were about 32\% (China), 6.2\% (Korea and Japan), $10.8 \%$ (Southeast Asia), and 20.5\% (Taiwan cities) (Figure 3A). For the PAHs (BaP and 16 PAHs), the average contributions ranged from $54.3-55.6 \%$ (frequency $34.4 \%$ ) for China, 43.7-43.8\% (frequency 7.1\%) for Korea and Japan, 30.6-32.0\% (frequency 12.5\%) for Southeast Asia, and 41.4-41.6\% (frequency 18.2\%) for Taiwan cities (Figure 3B and Table S3). The average PM2.5 contribution is about $37.5 \%$ from East Asian region (China, Japan and Korea), which is similar to the findings reported by (Chen et al., 2014), although by a different method.

Regarding seasonal contributions, the contributions from the East Asian region were usually observed in the early spring, autumn, and winter (Figure 4) with a high frequency of occurrence (Table S5), and high PM contributions of Type ET were observed in the summer (Table S4). The high PM contributions in the summer (54.2-61.5\%) were caused by a slow moving air mass that passed through south and central China_-areas that have intensive industrial activities (Lang et al., 2007; Li et al., 2006). For PM, the contributions were between $23.6-49.7 \%$ in the spring, $28.3-50.0 \%$ in the autumn, and $28.7-41.3 \%$ in the winter, which were attributed to the East Asian continent. The contributions of PAHs were about $26.4-53.2 \%, 38.9-53.9 \%$, and $43.0-64.3 \%$ for spring, autumn, and winter, respectively (Table S4). The high transboundary contribution observed in these seasons was caused by a decline or a weak northeasterly wind, accompanied by topographic features (the Central mountain 
ridge about 4000 meters high) facilitating pollutant accumulation in the study area. On the other hand, some winter cases (January and February) showed lower concentrations than the cases in spring and autumn (Figures S6 and S7). This could represent pollutants dispersed by the strong winter monsoon activities from the East Asian continent in the study area. A comparison between PM and PAHs showed that the contributions of PAHs were almost 1.5 times the contributions of PM in the winter, particularly from the East Asian continent (Table S4).

Figures S8B and S8E show the PAH composition patterns for the TBD case and NTBD in winter, respectively. The PAH pattern of the TBD case showed a relatively high proportion of compounds such as Ph, Flt, and Py when compared with the NTBD case. Comparison of the PAH composition patterns between the study area and China showed that the PAH pattern of the TBD case (Figure S8B) is comparable to the cases observed in Harbin (during the heating season) and Beijing (in winter) (Figure S8C and S8F), and the dominant source was coal combustion (Ma et al., 2010; Zhang et al., 2009). This confirmed the transboundary contribution of the East Asian continent to the study area in the TBD case. In our previous studies (Lai et al., 2011; 2013), the source apportionment results also indicated that the sources of PAHs in the study area were mainly related to vehicle emission and coal/wood combustion, in agreement with the findings mentioned above. This provides evidence that the high signal of coal combustion in the TBD cases observed in winter is related to heating activities in the East Asian continent.

Type SA and Type SAT were related to the source region of Southeast Asia. The frequency of occurrence of Type SA was higher in the summer, while Type SAT was observed in the other three seasons. The PM contributions to the study area were between $14.8-28.9 \%$ from Type SA and 14.9-41.8\% from Type SAT. Regarding PAHs, about $10.7-31.4 \%$ and $29.1-56.8 \%$ were contributed by Type SA and SAT, 
respectively (Table S3). Transboundary contributions from this area were relatively lower than from the other source regions (Figure 4 and Table S4) because of the meteorological conditions (prevailing southwesterly winds favor pollutant dispersion) and less industrial activity in this area in comparison with the other regions. The contribution comparison between PM and PAHs indicated higher Type SA contributions (31.0-31.4\%) to PAHs in the summer (Table S4). These contributions may be caused by biomass burning occurring in Southeast Asia. In addition, high contributions of PAHs (50.4-56.8\%) from Type SAT were also observed in the winter. Further investigation indicated that the contributions, primarily from south China, under slow moving air masses or stagnant atmospheric circulations resulted in pollutants that accumulated in the study area during the winter. Type TC, from other cities in Taiwan, is the other dominant source region associated with transboundary transport contribution (Figures 3A and B). The contributions of Type TC observed in each season were around $34.2-44.9 \%$ in PM and $32.7-48.3 \%$ in PAHs (Figure 4 and Table S4), with the highest frequency of occurrence in autumn (Table S5). The meteorological features of Type TC, such as stagnant atmospheric circulations and weak vertical mixing conditions, were the reason for high pollutant concentrations observed in the study area (Figures S6 and S7, bottom).

\subsection{Discussion of heavy pollution cases}

An application: a heavy pollution case study presented in this study. During the study period, 67 days were designated as "heavy pollution days" (HPDs), with a daily mean concentration of PM10 that exceeded $125 \mu \mathrm{g} \mathrm{m} \mathrm{m}^{-3}$ (24-h air quality standard, Taiwan EPA). About one-third of these days were defined as "health-effect days" (HEDs) with daily mean concentrations of PM10 that exceeded $150 \mu \mathrm{g} \mathrm{m}^{-3}$, which can trigger or slightly provoke symptoms for people with respiratory or cardiovascular diseases 
(TaiwanEPA 2014). In addition to the long-term exposure influences on human health, short-term exposure under high pollutant concentrations can cause adverse health effects as well (Laden et al., 2000). Considering the severe effects of these heavy pollution cases, the sources and the transboundary transport contributions of atmospheric pollutants (PM10, PM2.5, BaP, and 16PAHs) of these HPDs and HEDs were investigated further. Figure 5 illustrates the contributions of these cases from different transport pathways, and detailed information is listed in Table S6-S7. In general, the transboundary contributions of these cases are higher than the overall TBD contributions (Tables S4 and S6), with the exception of the cases of PM2.5 observed in the spring. The average contributions for PM were between 44.2-56.6\% for HPDs and 44.6-59.4\% for HEDs. Regarding PAHs, the average contributions were about 49.3-63.6\% and $45.2-59.4 \%$ for HPDs and HEDs, respectively (Table S6). The contributions from the East Asian region were around $47.8-63.5 \%$ and $47.9-59.3 \%$ for HPDs and for HEDs, respectively (Table S7). The maximum seasonal contributions of HPDs and HEDs appeared in autumn for both PM and PAHs; these high contributions (54.6-78.8\%) were associated with atmospheric circulation during seasonal transition period. The results were comparable to the aerosol events observed in response to synoptic weather patterns (Chuang et al., 2008) where about $49.5 \%$ of the aerosols were transported by a high pressure system from the East Asian continent to north Taiwan in combination with local pollution.

The evolution of winter monsoon activity with weak circulation or slowly moving air masses favors transboundary and local pollutant accumulation in the study area (Figure 5). The contributions observed from PM2.5 in the spring showed a reduction coupled with an increase of PM10 contributions. This situation may have been caused by some high PM concentration cases from East Asia that were associated with spring dust storms, which carried coarse particles more often than fine particles (Chen et al., 
2004). The contribution analysis suggested that air quality management of the study area should take transboundary transport contributions into account, especially air pollutants from the East Asian continent.

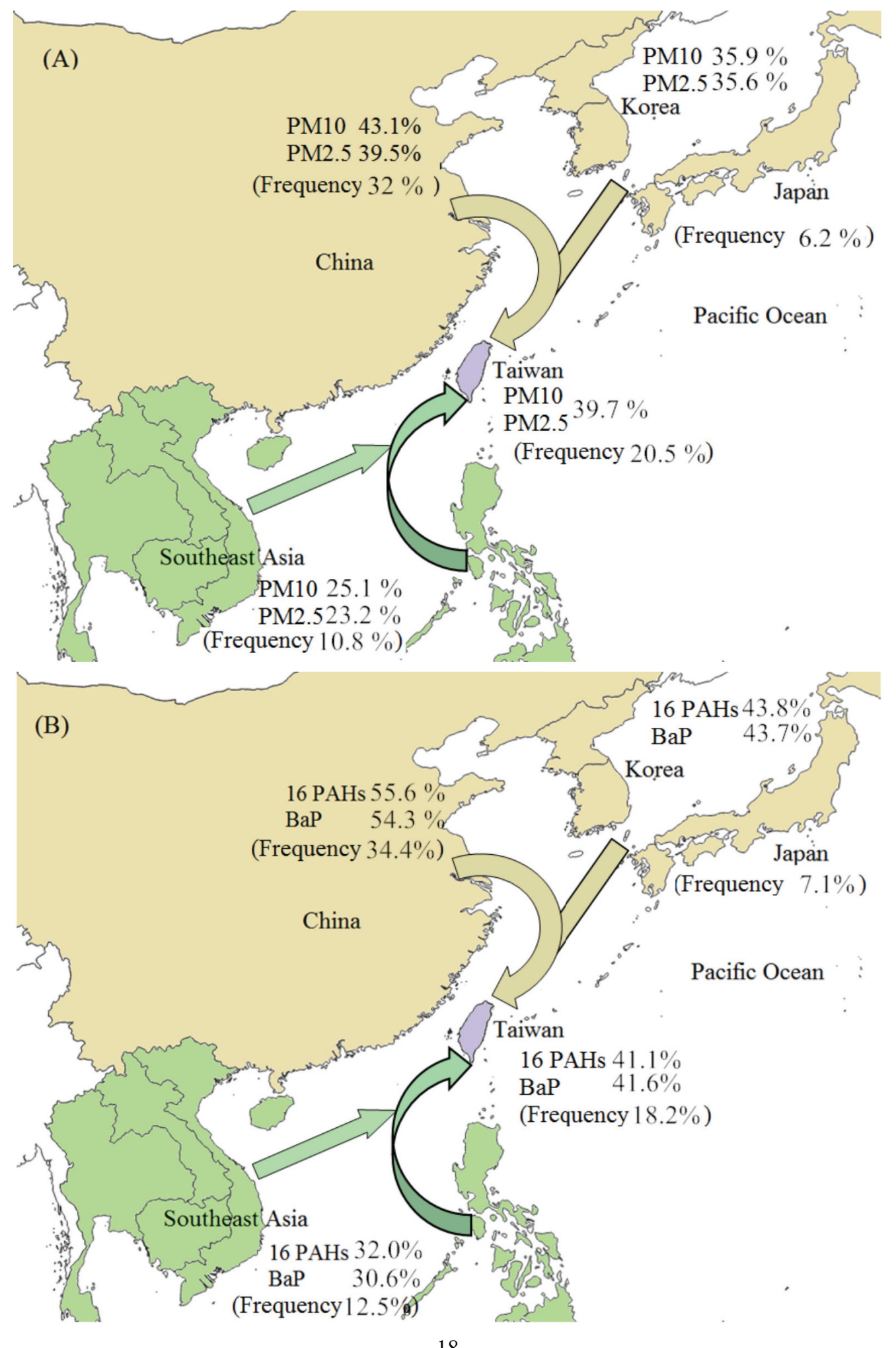


Figure 3. Annual contribution proportion and frequency of TBD occurrence (A) Particulate matter (PM10 and PM2.5) and (B) PAHs (BaP and 16 PAHs) from three source regions: East Asia (China, Japan, and Korea), Southeast Asia, and Taiwan cities.
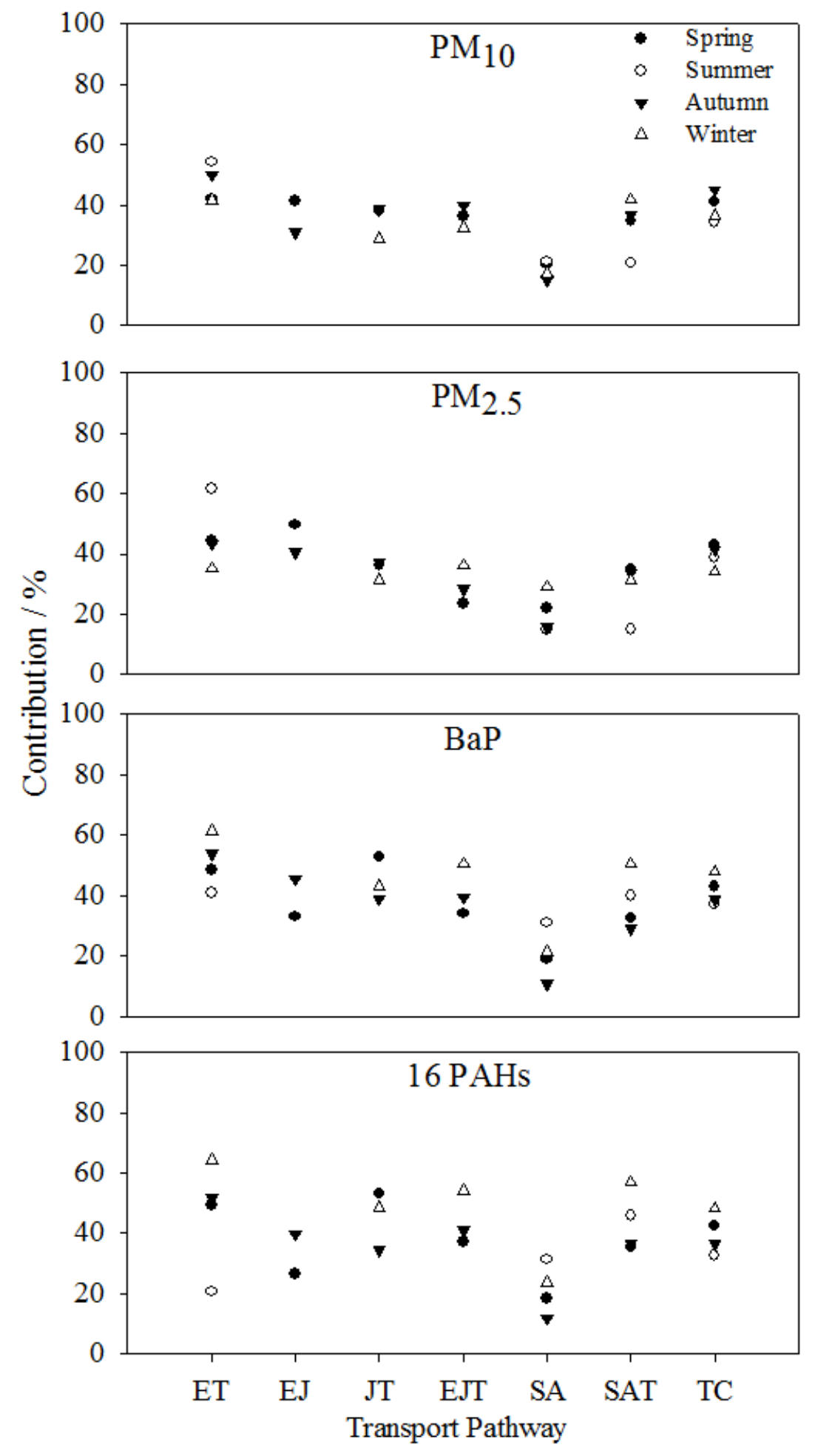

Figure 4. Seasonal average contribution proportion of PM10, PM2.5, BaP, and 16 PAHs from eight transport pathways between May of 2007 and April of 2009. The 
transport pathway types here are hybrid types. The types of ET, EJ, JT, and EJT represent the contributions from China (Type EC), Japan and Korea (Type JK) accompanying pollution from Taiwan other cities (Type TC). Type SA represents the contribution from Southeast Asian region and type SAT represents the contribution from Southeast Asia with Taiwan other cities.

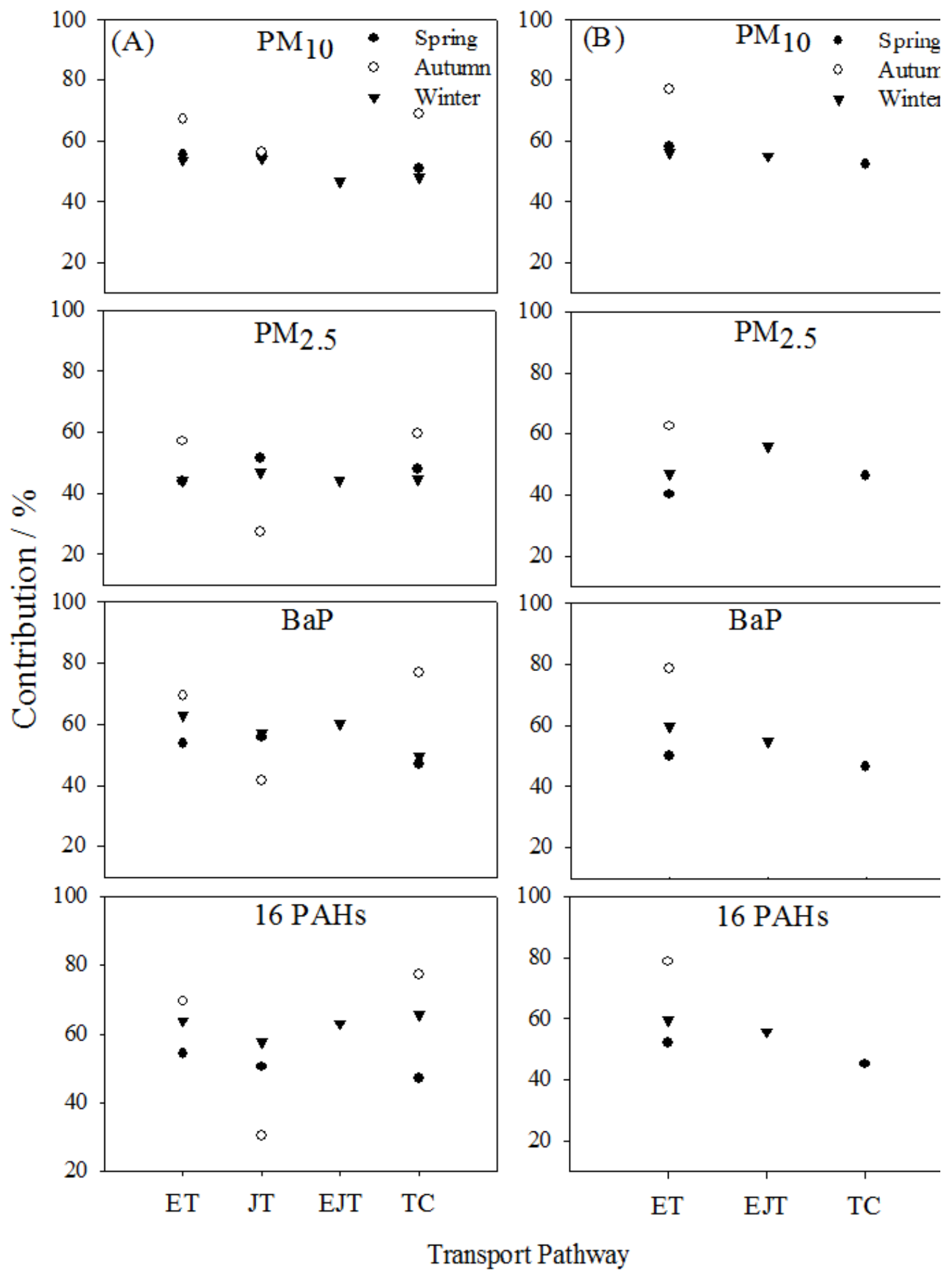

Figure 5. Seasonal average contribution proportion. (A) Contribution for the days with PM10 concentrations exceeding 24-h air quality standard $\left(125 \mu \mathrm{g} \mathrm{m}^{-3}\right)$ and (B) 
Contribution for the days with PM10 concentrations greater than $150 \mu \mathrm{g} \mathrm{m}^{-3}$. The types of ET, EJ, JT, and EJT represent the contributions from China (Type EC), Japan and Korea (Type JK) accompanying pollution from Taiwan other cities (Type TC). Type SA represents the contribution from Southeast Asian region and type SAT represents the contribution from Southeast Asia with Taiwan other cities.

\section{Conclusions}

A conceptual approach for quantifying transboundary pollution transport was established through trajectory analysis and pollutant concentration baseline simulation. A two-year back trajectory analysis categorized five representative transport pathways related to three source regions as East Asia, Southeast Asia, and Taiwan cities. Seasonal contributions showed that pollutants from the East Asian region occurred during spring, autumn, and winter, pollutants from the Southeast Asian region occurred during the spring and summer, and pollutants from Taiwan cities appeared in every season. Seasonal variation of contribution indicates that the air quality in the study area was affected by transboundary pollution transport as well as the variation of atmospheric circulation. The use of this approach showed that more than $50 \%$ of the heavy pollution cases in the study area can be attributed to transboundary contributions and the dominant source region was the East Asian region. A comparison between PM and PAHs indicates that the source of high PAH contributions (53.0-57.4\%) observed in the winter could be PAHs produced by heating activities on the East Asian continent. These results suggest that the model approach developed in this study is capable of quantifying transboundary transport contributions, especially for the areas lacking pollution emission data and regulatory monitoring of harmful air pollutants. In addition, the results suggest that pollution imported from neighboring countries to the study area should be carefully taken into consideration for air quality management.

\section{Acknowledgments}


The authors acknowledge the financial support from the National Science Council and the Ministry of Education of Taiwan, R.O.C., under Contract Numbers NSC 100-2611-M-110-010, NSC 101-2611-M-110-012, and DOE 01C030703. This study was also supported partially by Kaohsiung Medical University "Aim for the Top University Grant (Grant No. KMU-TP103A27).”

\section{References}

Akimoto H. Global Air Quality and Pollution. Science 2003; 302:1716-9.

Ayyub B M, McCuen R H. Numerical Methods for Engineers. New Jersey: Prentice-Hall; 1996.

Block M L, Calderón-Garcidueñas L. Air Pollution: Mechanisms of Neuroinflammation \& CNS Disease. Trends Neurosci 2009; 32:506-16.

Brunekreef B, Holgate S T. Air pollution and health. The Lancet 2002; 360:1233-42.

Calderón-Garcidueñas L, Mora-Tiscareño A, Ontiveros E, Gómez-Garza G, Barragán-Mejía G, Broadway J, Chapman S, Valencia-Salazar G, Jewells V, Maronpot R R, Henríquez-Roldán C, Pérez-Guillé B, Torres-Jardón R, Herrit L, Brooks D, Osnaya-Brizuela N, Monroy M E, González-Maciel A, Reynoso-Robles R, Villarreal-Calderon R, Solt A C, Engle R W. Air pollution, cognitive deficits and brain abnormalities: A pilot study with children and dogs. Brain and Cognition 2008; 68:117-27.

Chang S-C, Chou C C K, Chan C-C, Lee C-T. Temporal characteristics from continuous measurements of PM2.5 and speciation at the Taipei Aerosol Supersite from 2002 to 2008. Atmos Environ 2010; 44:1088-96.

Chen S-J, Hsieh L-T, Kao M-J, Lin W-Y, Huang K-L, Lin C-C. Characteristics of particles sampled in southern Taiwan during the Asian dust storm periods in 2000 and 2001. Atmos Environ 2004; 38:5925-34.

Chen T-F, Chang K-H, Tsai C-Y. Modeling direct and indirect effect of long range transport on atmospheric PM2.5 levels. Atmos Environ 2014; 89:1-9.

Chen T-F, Tsai C-Y, Chang K-H. Performance evaluation of atmospheric particulate matter modeling for East Asia. Atmos Environ 2013; 77:365-75.

Chin M, Diehl T, Ginoux P, Malm W. Intercontinental transport of pollution and dust aerosols: implications for regional air quality. Atmos Chem Phys 2007; 7:5501-17.

Chuang M-T, Chiang P-C, Chan C-C, Wang C-F, Chang E E, Lee C-T. The effects of synoptical weather pattern and complex terrain on the formation of aerosol events in the Greater Taipei area. Sci Total Environ 2008; 
399:128-46.

Daigle C C, Chalupa D C, Gibb F R, Morrow P E, Oberdörster G, Utell M J, Frampton M W. Ultrafine Particle Deposition in Humans During Rest and Exercise. Inhal Toxicol 2003; 15:539-52.

Draxler R R Rolph G D. NOAA Air Resources Laboratory. HYSPLIT (HYbrid Single-Particle Lagrangian Integrated Trajectory). 2014.

Genc S, Zadeoglulari Z, Fuss S H, Genc K. The Adverse Effects of Air Pollution on the Nervous System. J Toxicol 2012; 2012:23.

Grimmer G. Environmental carcinogens, polycyclic aromatic hydrocarbons: Chemistry, occurrence, biochemistry, carcinogeicity. Boca Raton, Fla. : CRC Press; 1983.

He M, Zheng J, Yin S, Zhang Y. Trends, temporal and spatial characteristics, and uncertainties in biomass burning emissions in the Pearl River Delta, China. Atmos Environ 2011; 45:4051-9.

Huebert B J, Bates T, Russell P B, Shi G, Kim Y J, Kawamura K, Carmichael G, Nakajima T. An overview of ACE-Asia: Strategies for quantifying the relationships between Asian aerosols and their climatic impacts. J Geophys Res-Atmos 2003; 108:8633.

IARC. IARC Monographs on the Evaluation of the Carcinogenicity of Chemicals to Humans. In: Polynuclear Aromatic Compounds, Part 3: Industrial Exposures in Aluminium Production, Coal Gasification, Coke Production, and Iron and Steel Founding, vol. 34 (Lyon). 1984.

Jaffe D, Anderson T, Covert D, Kotchenruther R, Trost B, Danielson J, Simpson W, Berntsen T, Karlsdottir S, Blake D, Harris J, Carmichael G, Uno I. Transport of Asian air pollution to North America. Geophys Res Lett 1999; 26:711-4.

Jeong U, Kim J, Lee H, Jung J, Kim Y J, Song C H, Koo J-H. Estimation of the contributions of long range transported aerosol in East Asia to carbonaceous aerosol and PM concentrations in Seoul, Korea using highly time resolved measurements: a PSCF model approach. J Environ Monitor 2011; 13:1905-18.

Junker C, Wang J-L, Lee C-T. Evaluation of the effect of long-range transport of air pollutants on coastal atmospheric monitoring sites in and around Taiwan. Atmos Environ 2009; 43:3374-84.

Kaiser J. Mounting Evidence Indicts Fine-Particle Pollution. Science 2005; 307:1858-61.

Kajino M, Sato K, Inomata Y, Ueda H. Source-receptor relationships of nitrate in Northeast Asia and influence of sea salt on the long-range transport of nitrate. Atmos Environ 2013; 79:67-78. 
Kim C, Jung S H, Kang D R, Kim H C, Moon K T, Hur N W, Shin D C, Suh I. Ambient Particulate Matter as a Risk Factor for Suicide. Am J Psychiatry 2010; 167:1100-7.

Krewski D, Michael Jerrett, Richard T Burnett, Renjun Ma, Edward Hughes, Yuanli Shi, Michelle C Turner, C Arden Pope III, George Thurston, Eugenia E Calle, Thun a M J. Extended Follow-Up and Spatial Analysis of the American Cancer Society Study Linking Particulate Air Pollution and Mortality. Health Effect Institute; 2009.

Laden F, Neas L M, Dockery D W, Schwartz J. Association of fine particulate matter from different sources with daily mortality in six U.S. cities. Environ Health Persp 2000; 108:941-7.

Laden F, Schwartz J, Speizer F E, Dockery D W. Reduction in Fine Particulate Air Pollution and Mortality. Am J Resp Crit Care 2006; 173:667-72.

Lai I C, Chang Y-C, Lee C-L, Chiou G-Y, Huang H-C. Source identification and characterization of atmospheric polycyclic aromatic hydrocarbons along the southwestern coastal area of Taiwan - with a GMDH approach. Journal of Environmental Management 2013; 115:60-8.

Lai I C, Lee C-L, Zeng K-Y, Huang H-C. Seasonal variation of atmospheric polycyclic aromatic hydrocarbons along the Kaohsiung coast. Journal of Environmental Management 2011; 92:2029-37.

Lang C, Tao S, Zhang G, Fu J, Simonich S. Outflow of Polycyclic Aromatic Hydrocarbons from Guangdong, Southern China. Environ Sci Techno 2007; 41:8370-5.

Lelieveld J, Berresheim H, Borrmann S, Crutzen P J, Dentener F J, Fischer H, Feichter J, Flatau P J, Heland J, Holzinger R, Korrmann R, Lawrence M G, Levin Z, Markowicz K M, Mihalopoulos N, Minikin A, Ramanathan V, de Reus M, Roelofs G J, Scheeren H A, Sciare J, Schlager H, Schultz M, Siegmund P, Steil B, Stephanou E G, Stier P, Traub M, Warneke C, Williams J, Ziereis H. Global Air Pollution Crossroads over the Mediterranean. Science 2002; 298:794-9.

Li J, Zhang G, Li X D, Qi S H, Liu G Q, Peng X Z. Source seasonality of polycyclic aromatic hydrocarbons (PAHs) in a subtropical city, Guangzhou, South China. Sci Total Environ 2006; 355:145-55.

Lighty J S, Veranth J M, Sarofim A F. Combustion Aerosols: Factors Governing Their Size and Composition and Implications to Human Health. J Air Waste Manag Assoc 2000; 50:1565-618.

Lin C-Y, Liu S C, Chou C C-K, Huang S-J, Liu C-M, Kuo C-H, Young C-Y. Long-range transport of aerosols and their impact on the air quality of Taiwan. Atmos Environ 2005; 39:6066-76. 
Lin C-Y, Wang Z, Chen W N, Chang S Y, Chou C C K, Sugimoto N, Zhao X. Long-range transport of Asian dust and air pollutants to Taiwan: observed evidence and model simulation. Atmos Chem Phys 2007; 7:423-34.

Ma W-L, Li Y-F, Qi H, Sun D-Z, Liu L-Y, Wang D-G. Seasonal variations of sources of polycyclic aromatic hydrocarbons (PAHs) to a northeastern urban city, China. Chemosphere 2010; 79:441-7.

Mauzerall D L, Narita D, Akimoto H, Horowitz L, Walters S, Hauglustaine D A, Brasseur G. Seasonal characteristics of tropospheric ozone production and mixing ratios over East Asia: A global three-dimensional chemical transport model analysis. J Geophys Res-Atmos 2000; 105:17895-910.

Naja M, Akimoto H. Contribution of regional pollution and long-range transport to the Asia-Pacific region: Analysis of long-term ozonesonde data over Japan. J Geophys Res-Atmos 2004; 109:D21306.

Nam J, Wang Y, Luo C, Chu D A. Trans-Pacific transport of Asian dust and CO: accumulation of biomass burning $\mathrm{CO}$ in the subtropics and dipole structure of transport. Atmos Chem Phys Discuss 2009; 9:12899-926.

Pope III C A, Burnett R T, Thun M J, Calle E E, Krewski D, Ito K, Thurston G D. LUng cancer, cardiopulmonary mortality, and long-term exposure to fine particulate air pollution. JAMA 2002; 287:1132-41.

Pope III C A, Burnett R T, Thurston G D, Thun M J, Calle E E, Krewski D, Godleski J J. Cardiovascular Mortality and Long-Term Exposure to Particulate Air Pollution: Epidemiological Evidence of General Pathophysiological Pathways of Disease. Circulation 2004; 109:71-7.

Primbs T, Simonich S, Schmedding D, Wilson G, Jaffe D, Takami A, Kato S, Hatakeyama S, Kajii Y. Atmospheric Outflow of Anthropogenic Semivolatile Organic Compounds from East Asia in Spring 2004. Environ Sci Techno 2007; 41:3551-8.

Rolph G D. Real-time Environmental Applications and Display sYstem (READY) Website. 2014.

Taiwan EPA. Air Quality Monitoring Network. 2014.

U.S.EPA. Office of the Federal Registration (OFR), Appendix A: priority pollutants. 1982.

Wagstrom K M, Pandis S N. Contribution of long range transport to local fine particulate matter concerns. Atmos Environ 2011; 45:2730-5.

Wang S, Zheng J, Fu F, Yin S, Zhong L. Development of an emission processing system for the Pearl River Delta Regional air quality modeling using the SMOKE model: Methodology and evaluation. Atmos Environ 2011; 45:5079-89.

WHO. Health risks of persistent organic pollutants from long-range 
transboundary air polluton. Copenhagen, Denmark: WHO regional office for Europe; 2003.

WHO. Air quality guide lines: Global update 2005: Particulate matter, ozone, nitrogen dioxide, and sulfur dioxide. . Copenhagen, Denmark: World Health Organization; 2006.

Wilkening K E, Barrie L A, Engle M. Trans-Pacific Air Pollution. Science 2000; 290:65-7.

Yang X-Y, Okada Y, Tang N, Matsunaga S, Tamura K, Lin J-M, Kameda T, Toriba A, Hayakawa K. Long-range transport of polycyclic aromatic hydrocarbons from China to Japan. Atmos Environ 2007; 41:2710-8.

Zhang L, Jacob D J, Boersma K F, Jaffe D A, Olson J R, Bowman K W, Worden J R, Thompson A M, Avery M A, Cohen R C, Dibb J E, Flock F M, Fuelberg H E, Huey L G, McMillan W W, Singh H B, Weinheimer A J. Transpacific transport of ozone pollution and the effect of recent Asian emission increases on air quality in North America: an integrated analysis using satellite, aircraft, ozonesonde, and surface observations. Atmos Chem Phys 2008; 8:6117-36.

Zhang Y, Shen H, Tao S, Ma J. Modeling the atmospheric transport and outflow of polycyclic aromatic hydrocarbons emitted from China. Atmos Environ 2011; 45:2820-7.

Zhang S, Zhang W, Wang K, Shen Y, Hu L, Wang X. Concentration, distribution and source apportionment of atmospheric polycyclic aromatic hydrocarbons in the southeast suburb of Beijing, China. Environ Monit Assess 2009; 151:197-207.

Zheng J, Zhang L, Che W, Zheng Z, Yin S. A highly resolved temporal and spatial air pollutant emission inventory for the Pearl River Delta region, China and its uncertainty assessment. Atmos Environ 2009; 43:5112-22. 